1 New perspectives on the ecology of early domestic fowl: an interdisciplinary approach.

2 Jacqueline Pitt ${ }^{\mathrm{a}}$, Phillipa Gillingham ${ }^{\mathrm{a}}$, Mark Maltby ${ }^{\mathrm{b}}$ and John R. Stewart ${ }^{\mathrm{a}}$

$3 \quad{ }^{a}$ Department of Life and Environmental Sciences, Bournemouth University, Talbot Campus, Poole

$4 \quad{ }^{\mathrm{b}}$ Department of Archaeology, Anthropology and Forensic Science, Bournemouth University, Talbot Campus, Poole

6 Keywords: Red Junglefowl, Chicken, Domestication, Ecological niche models, Maxent

8 Abstract: Introduced into Europe during the Bronze- and Iron Ages as an exotic, non-native species, very little is 9 currently understood about the origins and spread of early domestic fowl, Gallus gallus domesticus. Ecological niche modelling of extant Red Junglefowl, Gallus gallus, presents a unique opportunity to examine historical ecological implications associated with its descendant, the chicken, in early stages of domestication. We model the environmental conditions associated with Red Junglefowl populations both in south-east Asia, where the bird originates, and populations transported further afield as a consequence of human interaction. This allows us to establish the full extent of the ecological tolerance of the ancestor bird. We show that potential for suitable sets of environmental conditions for Red Junglefowl in Europe ranges from poor to limited, based on both current climate and when projecting to mid-Holocene (ca. 4000BC) climate simulations. This suggests that human intervention played a vital contribution during early domestication to ensure the future widespread success of the chicken. These conclusions offer new insights into the archaeological evidence. We identify areas in the native range as the probable location of first domestication, and not China as has been suggested. We suggest that a dispersal route into Europe via the Mediterranean offers the best ecological potential to aid survival for a recently domesticated version of this species. Identifying the environmental tolerances of Red Junglefowl may also aid future conservation of this species, now highly endangered in its true wild form.

1. Introduction: With a population of over 20 billion (Chemnitz and Becheva 2014) and near global distribution, the domestic fowl or chicken Gallus gallus domesticus is the most widespread domestic animal. Chickens have influenced many facets of human life, including ritual, religion, culture, and identity; in addition to their more commonly recognised uses as producers of meat, eggs and feathers. While it is widely accepted that domestic fowl are descended from junglefowl, very little is understood regarding their origins and dispersal around the globe. Despite the success of the chicken, the junglefowl has also survived, offering an excellent opportunity to examine the ancestor in order to explore issues faced by recently domesticated species, including responses to new environments and the corresponding implications of animal husbandry.

There are four extant species of junglefowl, namely Red Junglefowl, Gallus gallus; Grey Junglefowl, Gallus sonneratii; Sri Lanka Junglefowl, Gallus lafayetii; and Green Junglefowl, Gallus varius. Originating in Southern and 
Southeast Asia, India and Indonesia, and predominantly occupying tropical rainforest environments, they have historically been confined to this range by geographical barriers (Figure 1).

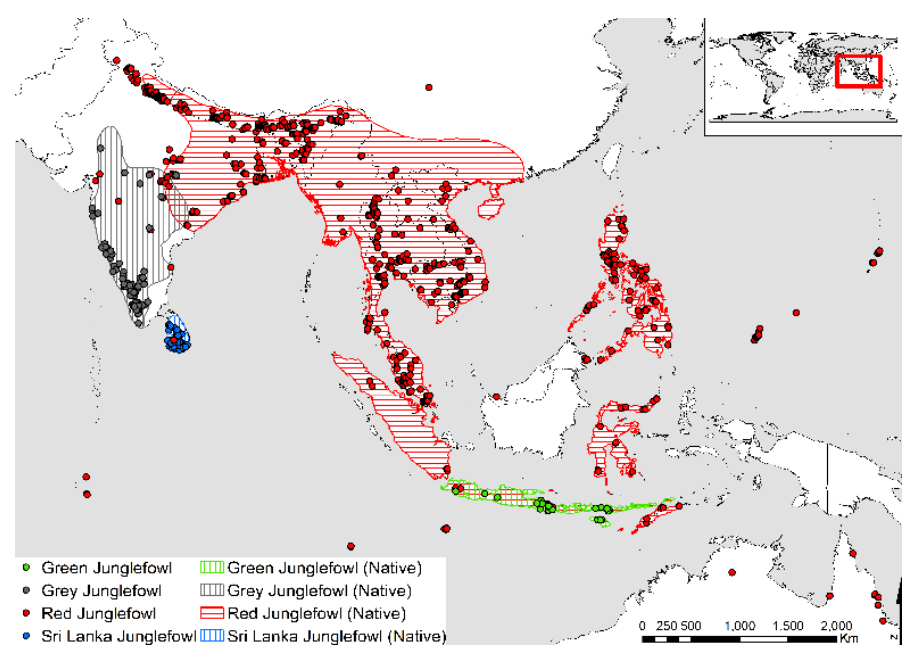

Figure 1 Geographic range (hashed area, IUCN Redlist) with occurrence points (gbif.org) for all four junglefowl species

There are very few archaeological specimens found outside of the native range which are identified as Red Junglefowl, rather than chicken; although whether this is because bones bearing Gallus traits are automatically identified as chicken in areas outside the native junglefowl range is unclear. Early chickens are often noted to be of similar size to Red Junglefowl. Junglefowl (and chickens), however, are non-migratory with limited flight capability, rendering mountains and large bodies of water impassable. Inhospitable environments such as desert or semi-desert lacking corridors of environmental suitability further restrict natural dispersal to areas which would otherwise be suitable. Red Junglefowl have been transported by humans to most continents in more recent times, but there are no reported occurrences of the other three species outside their native ranges. Of the four junglefowl species, genetic studies have identified the contribution of the Red- and Grey- Junglefowl to the domestic mix. Red Junglefowl is the dominant ancestor for early domestic fowl, with hybridization with Grey Junglefowl occurring millennia later. (Eriksson et al. 2008; Girdland Flink et al. 2014).

As yet, there is no clear chronology for the early domestication of the chicken, largely due to potential misidentification of the remains, lack of secure context or poor dating evidence (Harrison 1980; Stewart 2005; Stewart 2007; Bochenski 2008). Multiple rather than single origins of domestication are now accepted (Liu et al. 2006; Kanginakudru et al. 2008; Xiang et al. 2014), with mtDNA providing support for localised domestication events in South Asia, Northeast India, Southwest China, and a further event in Southwest China and Southeast Asia (Miao et al. 2013). The earliest proposed domestication event is Nanzhuangtou, China ca.8050BC (Xiang et al. 2014); but this has been contested (Peters et al. 2015; Xiang et al. 2015; Eda et al. 2016). Eda et al. (2016) recently reappraised evidence at other early Chinese sites (West and Zhou 1988) concluding that the earliest specimens are not chicken, but one or more of the other 53 Phasianidae species found in China. This leaves the oldest evidence from a secure archaeological context found in Asia at Happaran Culture sites in the Indus valley, India, ca. 2500BC (Zeuner 1963; Fuller 2006). 
An eastward expansion of the domestic chicken via Oceania to South America has been demonstrated using archaeological evidence (Storey et al. 2007; Storey et al. 2008; Fitzpatrick and Callaghan 2009) and DNA analysis (Gongora et al. 2008; Storey et al. 2012; Thomson et al. 2014). Despite its archaeological relevance as a proxy for human dispersal and cultural associations, there has been less consideration of its route westwards and into Europe, largely due to due to a lack of collated zooarchaeological evidence. Routes proposed include dispersal into Europe by way of a northern route into China, spreading to Europe via Russia (West and Zhou 1988); or west via Phoenician trade routes (Becker 2013). These correspond with some of the earliest proposed evidence outside of Asia, including Bulgaria, ca. 5550BC (Boev 2009), the Southern Levant, ca. 2500BC (Perry-Gal et al. 2015) and Iberia, ca. 2000BC (von den Driesch 1973). Recent literature highlighting issues with other early evidence (Kyselý 2010; Peters et al. 2015), suggests that these unusually early dates for European sites may require verification. Evidence is present in secure archaeological contexts from at least the Iron Age in Europe, ca. 500BC (Hamilton 2000; Kyselý 2010; Strid 2015). Placing archaeological evidence in the context of environmental suitability can be used to aid interpretation of these early specimens.

Ecological niche models (ENM) are frequently used in ecological research to better understand the environmental conditions that enable a species to persist. They predict the presence of suitable conditions, but not where the species will necessarily be found. Estimating the latter benefits from consideration of biotic and geographical factors, outside the scope of ENM and this study. Various methods exist for performing ENM. However, maximum entropy modelling (Maxent) has been demonstrated to work well with presence-only data ${ }^{1}$, such as the data available for this study (Phillips et al. 2004; Elith et al. 2006; Banks et al. 2013). It is a machine learning method which takes the average value for a set of random sample points within a calibrated region (study area where the species is found and able to survive within geographical boundaries and environmental tolerance). It calculates how this differs from known sets of environmental values at locations the species is known to occur to estimate the probability of occurrence given particular environmental conditions. This can then be projected to other regions of the world or other time-periods (Phillips et al. 2006).

Modelling the ecological niche of Red Junglefowl enables evaluation of how far the chicken today has conserved or shifted its fundamental niche. The fundamental niche indicates where the species can survive, as opposed to the realised niche, which relates where the species is actually found. The former is of most importance to this study. Wild populations within the region of origin may not represent the full fundamental niche of the species. Geographical barriers limiting movement mean that any niche based on these observations more closely reflects a realised niche and ENM enables us to predict the consequences of removing these barriers to movement. Comparing the niches of native wild populations to populations which are known to have already been transported by humans to locations that would otherwise be geographically inaccessible, identifies how well Red Junglefowl acclimate to different environments and latitudes. The combination of both niches establishes the full suite of environmental tolerance for this species, including those that have been subject to human interaction and, inevitably, some level of artificial selection. Higher

\footnotetext{
${ }^{1}$ as opposed to data with known presences and confirmed absences
} 
environmental suitability values indicate where the species is more likely to be able to survive and breed. First domestication of a species in an area of poor environmental suitability is unlikely to be successful. Lower suitability would necessitate increased assistance by other means, i.e. direct (feeding and housing) or indirect (selection during breeding) human intervention. The earliest examples of domestic fowl would have had limited chance to evolve distinct physiological and morphological traits from their ancestor. Therefore, identifying potential for suitable environmental conditions at archaeological sites with early evidence of chicken can inform not only the likelihood for the site being a location of first domestication, but also the extent of human effort required during early domestication to ensure survival of this newly domesticated, exotic species.

2. Materials and Methods: ENM input requires a dataset of occurrence points (section 2.1) and environmental variable layers (section 2.3) for the relevant geographic extents (section 2.2).

2.1 We used observation data for Red Junglefowl post-1950 downloaded from the Global Biodiversity Information Facility (GBIF.org (11th February 2016)). Observations which were described as domestic, were unclearly georeferenced, exact duplicates, or were located outside of the boundary of the global terrestrial environmental layers were removed. This resulted in a presence-only dataset of 2356 occurrence points for the ENMs. There is a danger with this type of large available dataset that sampling bias towards more easily accessible regions could bias the random background data for the ENM. However, Maxent contains inbuilt functionality to account for this (Phillips et al. 2009).

These occurrences vary from wild Red Junglefowl in National Parks or protected forests, to managed reserves, to birds inhabiting urban settings (including zoos, botanical gardens and residential properties). 'Wild' Red Junglefowl are most likely to be a hybridised version of wild birds, since hybridisation between 'true' wild Red Junglefowl and domestic fowl has resulted in very limited populations retaining their original morphology, making the Red Junglefowl, in its original wild form, now highly endangered (Peterson and Brisbin 1998; Gering et al. 2015). As our aim was to understand the broadest ecological tolerance of the species, the observations were not subdivided by habitat type. PCA analysis (Figure 2) did identify differences in response to environmental conditions depending on whether the bird is within its natural range or has been subject to human selection and transportation. Therefore, we divided the observations into two groups accordingly. Hereafter, observations located in suitable environments which are geographically accessible without human help are defined as 'indigenous', while all other observations are defined as 'non-indigenous'. Once transported, 'non-indigenous' occurrences are subject to the same dispersal limitations as those within the natural range, due to lack of migration or capacity for flight. 


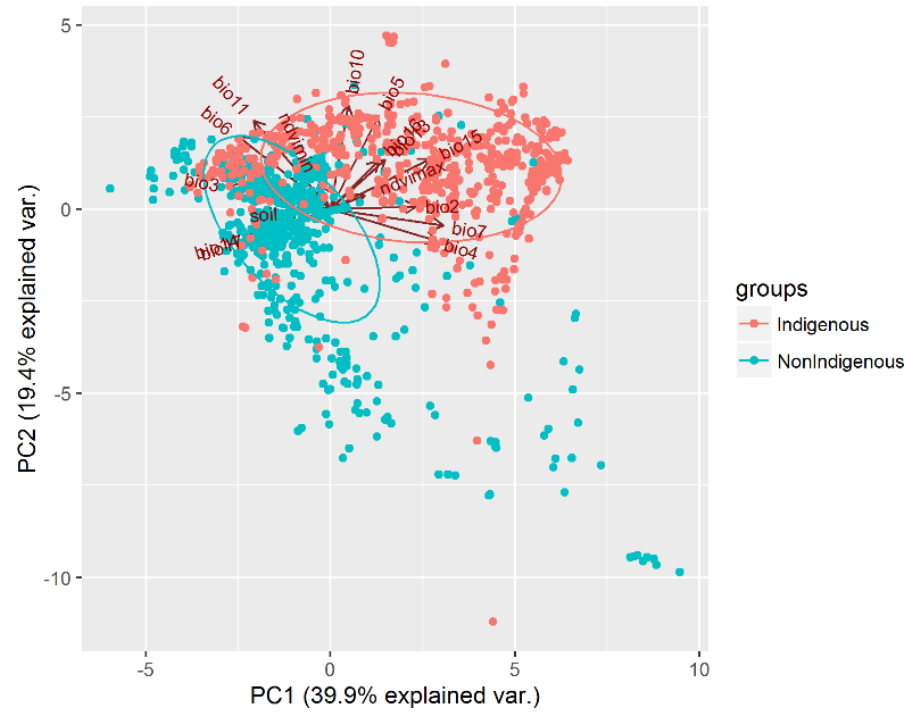

Figure 2 Principal component analysis of all variables (present climate) and occurrences by geographic location. Red points represent occurrences within Asia (the continent of origin for Red Junglefowl), while green points represent all other occurrences. Spatial clustering indicates differences in response to environmental conditions based on geographic location.

Recent changes affecting the habitat of Red Junglefowl due to human activity in the native region could affect interpretation when projecting to the past. With some exceptions, such as Mexico City, urbanisation occurs more frequently at low elevations. To assess the potential impact of this, altitude (CGIAR Consortium for Spatial Information 2008) over the past 25 years at the location of known observations within its native range was analysed to gauge the impact of the spread of urbanisation. No significant changes in elevation are observed over this time period, indicating that the species has not been forced to alter their habitat by moving to higher elevations to survive.

2.2 The study area comprises calibrated and projected global ranges for the indigenous and non-indigenous Red Junglefowl. Calibrated ranges for the final models are defined by potential species movement (determined by convex hull based on known occurrences), and which are at least minimally environmentally suitable (ENM suitability value $>0$, calculated using preliminary ENM within geographically accessible areas) (Figure 3).

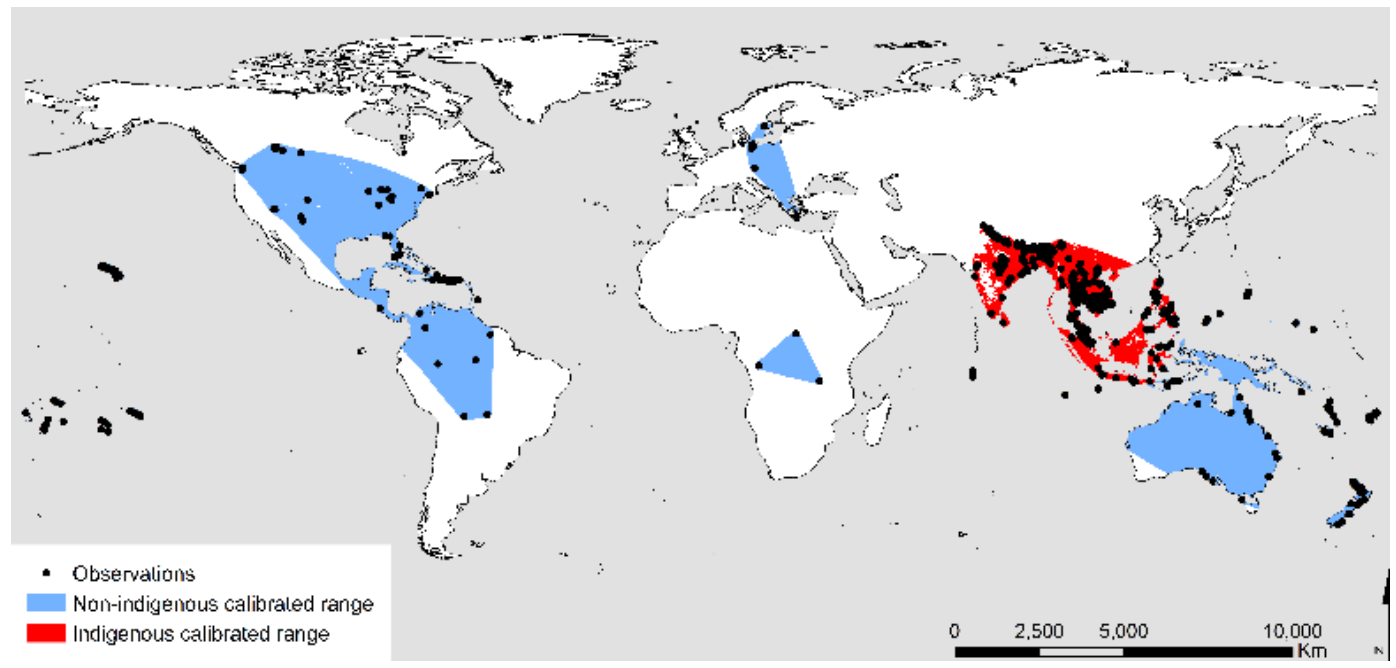

Figure 3 Observation locations (points) and extent of indigenous (red) and non-indigenous (blue) calibrated ranges 
As mentioned above, dispersal outside of the native range requires transportation by humans. For this reason, the global projection range is not limited geographically, as humans have transported the chicken a long way beyond its native range. However, it is limited environmentally. Maxent uses an exponential model for probabilities, which can result in large predicted suitability values for environmental conditions outside the range present in the study area (Phillips et al. 2006). To avoid spurious predictions, global projection was limited to areas of the world where the values of the environmental variables fall within the range of those in the calibrated area (Ficetola et al. 2007).

2.3 Environmental variables were selected based on relevance to the biological requirements of Red Junglefowl. Minimum and maximum temperatures determine thermal tolerance, which has been demonstrated to limit species distributions (Araujo et al. 2013; Khaliq et al. 2014), with minimum winter temperature shown to be the best predictor of variation in avian metabolic scope, outperforming all other thermal variables (Stager et al. 2015). Seasonal variation identifies tolerance for change by predominantly equatorial species. Precipitation variables explain the availability of drinking water. Soil type explains the availability of grit, used to macerate ground-foraged food in the crop due to a lack of stomach acid. Vegetation cover is critical for food, shelter and protection from predation. The latter was unavailable for past climate simulations, due to changes in vegetation cover between the time periods under consideration.

We used Bioclimatic (BioClim) variables for both current climate and the mid-Holocene (ca. 4000BC) from the WorldClim database at 2.5 arc-minute resolution, or approx. $5 \mathrm{~km}$ at the equator (Hijmans et al. 2005). Current climate is likely to be similar to that experienced by early chickens in Europe, ca. 500BC, a period which corresponds with the improving climate of the Middle Iron Age to Roman period, and is therefore used as a proxy. Projecting to the midHolocene enables comparison of suitability for a time period even closer to some of the earliest evidence for chicken. Annual average vegetation cover was compiled from the individual 0.1-degree resolution 1-month Terra/Modis Normalized Difference Vegetation Index (NDVI) (Nasa Earth Observations 2015) for 2008, the mean year for the observation points. We used the 'Harmonized World Soil Dataset - Major Soil Groups' (FAO/IIASA/ISRIC/ISSCAS/JRC 2009) to denote soil type; and degree of slope was calculated using the standard function in ArcGIS (v.10.2.2), based on the SRTM 250m digital elevation model (CGIAR Consortium for Spatial Information 2008). Final variable selection (Table 1) was chosen according to least correlation and greatest importance to the species. Importance was assessed using the Maxent jackknife test of variable importance from a preliminary model using all variables and occurrences.

\begin{tabular}{|l|l|l|}
\hline Variable & Description & Purpose \\
\hline Bio4 & Temperature Seasonality (standard deviation *100) & Seasonality \\
\hline Bio5 & Max Temperature of Warmest Month & Thermal tolerance \\
\hline Bio6 & Min Temperature of Coldest Month & Thermal tolerance \\
\hline Bio13 & Precipitation of Wettest Month & Water availability \\
\hline Bio14 & Precipitation of Driest Month & Water availability \\
\hline
\end{tabular}




\begin{tabular}{|l|l|l|}
\hline Bio15 & Precipitation Seasonality (Coefficient of Variation) & Seasonality \\
\hline Ndvimin & Terra/Modis NDVI, annual minimum (0-255) & Vegetation cover \\
\hline Ndvimax & Terra/Modis NDVI, annual maximum (0-255) & Vegetation cover \\
\hline Soil & Soil type (categorical variable) & Grit availability \\
\hline
\end{tabular}

Table 1 Environmental variables selected for final 17\% lels

179 Ecological niche models for this study were run using Maxent for 100 replicates with a subsample of $30 \%$ test data, random seed, and a regularization parameter of 2.5 to prevent overfitting. Each replicate uses different random sets of training and test data, and the results presented within this paper represent averages. Model performance was evaluated using AUC, the area under the receiver operating curve, which produces a value between 0-1 based on how well the model predicts presence at the training locations (see Phillips et al. 2006 for a full discussion of the validity of AUC in Maxent). A value of 0.5 would indicate no better than expected by chance, 0.7-0.9 indicates reasonable performance, and above 0.9 indicates very good performance (Swets 1988). Thresholds for environmental suitability were calculated from the output summary using a sensitivity-specificity equality approach (see Liu et al. 2005 for evaluation of determining thresholds in niche modelling).

3. Results: Changing altitude of observations from 1950 to present was analysed to assess potential modern influences on junglefowl range. Little change in altitude was observed, suggesting that movement to higher elevations to avoid urbanisation has not occurred. 
(a)

(b)
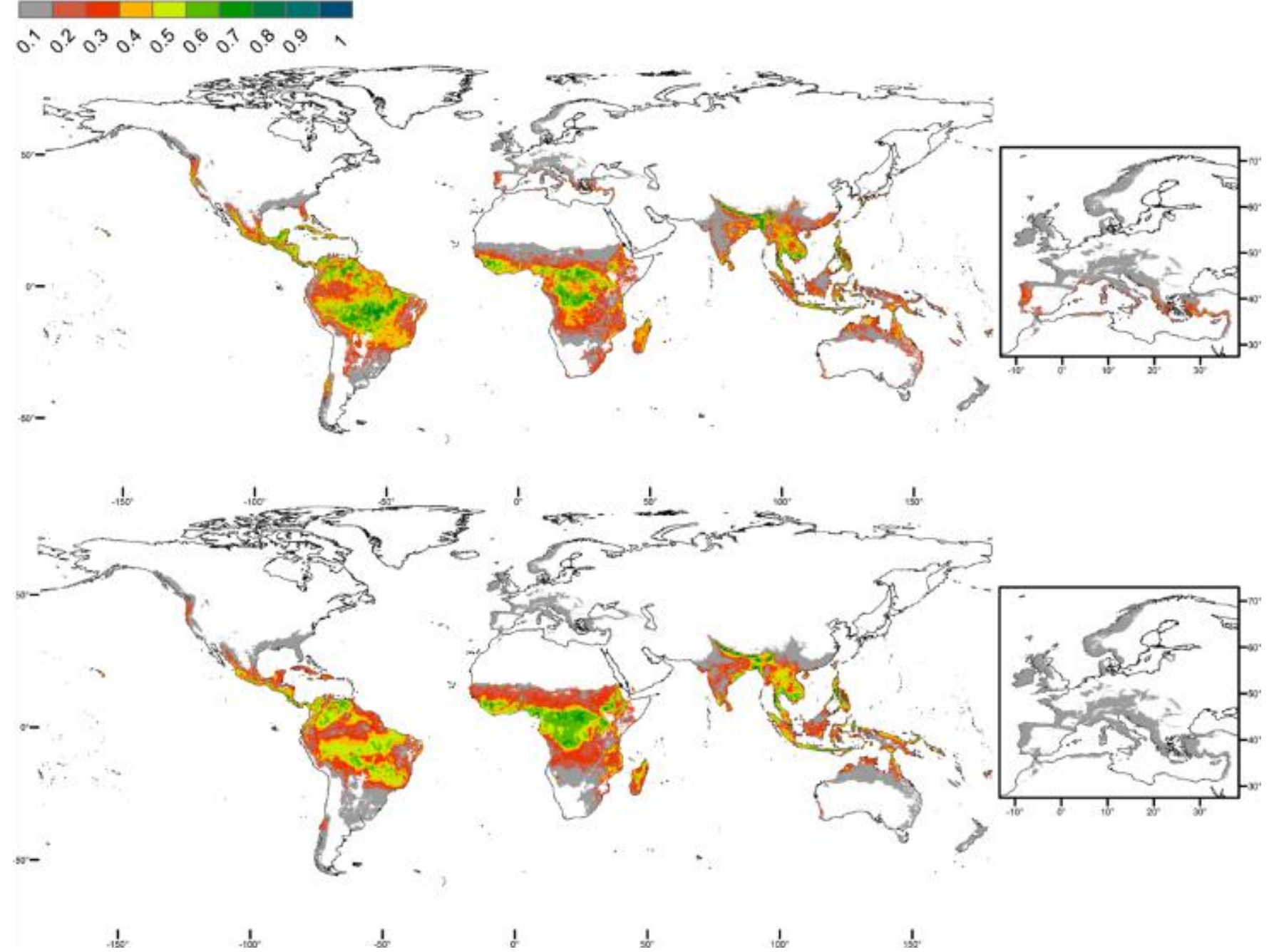

Figure 4 Global projections of predicted environmental suitability for Red Junglefowl ( $n=796)$ based on indigenous observations for current climate (a), past climate (b). Suitability threshold=0.4; areas in white fall outside the range of calibration area

The performance of the ENMs can be considered reasonable to good, with AUC values ranging from 0.76 to 0.95. Areas predicted to be suitable for the Red Junglefowl, both currently and in the past, based on indigenous occurrences, largely lie between the latitudes of the tropics of Cancer and Capricorn (Figure 4). The most suitable sets of conditions are found within its native range, central Africa, and the Amazon basin. For indigenous populations, precipitation and minimum vegetation cover are most important. Probability of suitable conditions increases with high rainfall in the wettest month, corroborating the exclusion of much of Europe from the global projection due to low rainfall relative to the tropics. An optimal vegetation cover is indicated by a positive relationship for increased levels of minimum vegetation, but a negative relationship when the maximum vegetation is too dense. Apart from very small pockets in Portugal, Greece, Montenegro and Albania, Europe is unlikely to contain suitable environmental conditions for indigenous Red Junglefowl, either now or when projected back to 4000BC. of high potential (Figure 5). The most suitable sets of conditions are found in the South Pacific islands and New 
Zealand; Kenya, Tanzania and the southern coast of South Africa; eastern Madagascar; the Caribbean islands; and eastern Brazil. Above threshold potential for suitable conditions is present in Europe, with fairly good potential in north-west France, north-west Iberia, and the south coast of Ireland. Past projection predicts better potential at more northerly latitudes than current climate simulations. For non-indigenous populations, temperature seasonality and temperature range are most important. Seasonality increases with distance from the equator, requiring much greater tolerance within an annual cycle. Probability of suitable conditions decreases with warmer temperatures in the warmest month, and increases with warmer temperatures in the coldest month, reflecting thermal tolerance.

\section{Suitability Scale}

(a)
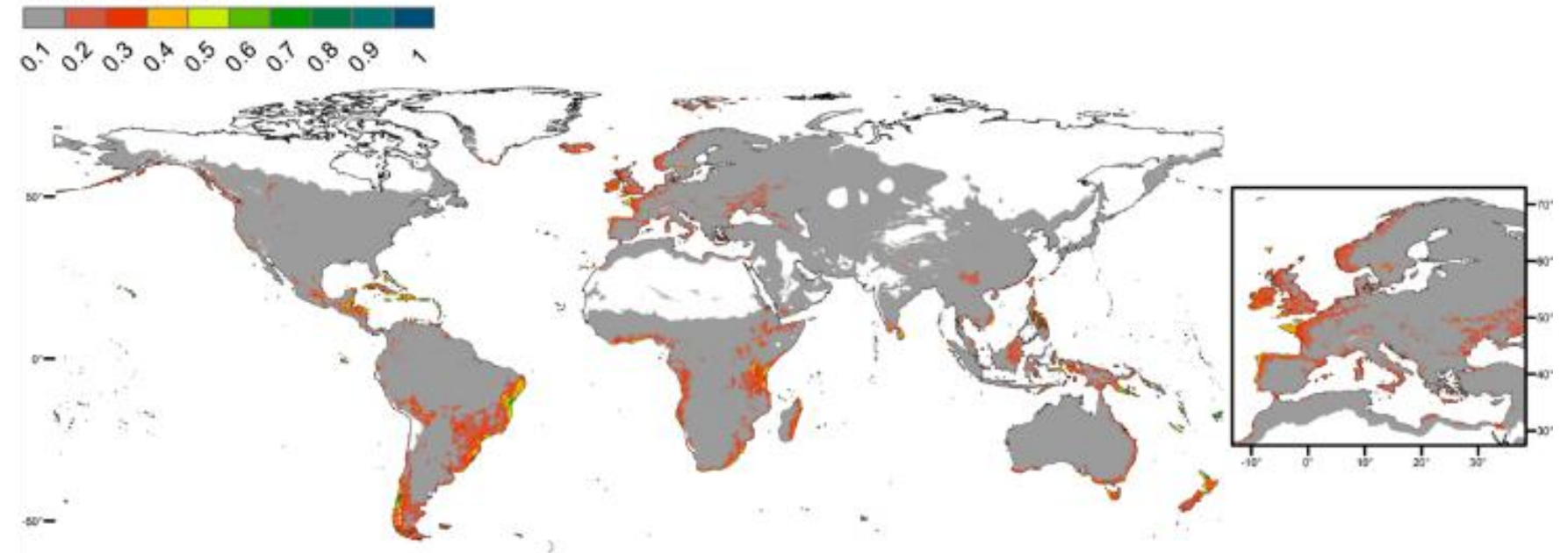

(b)

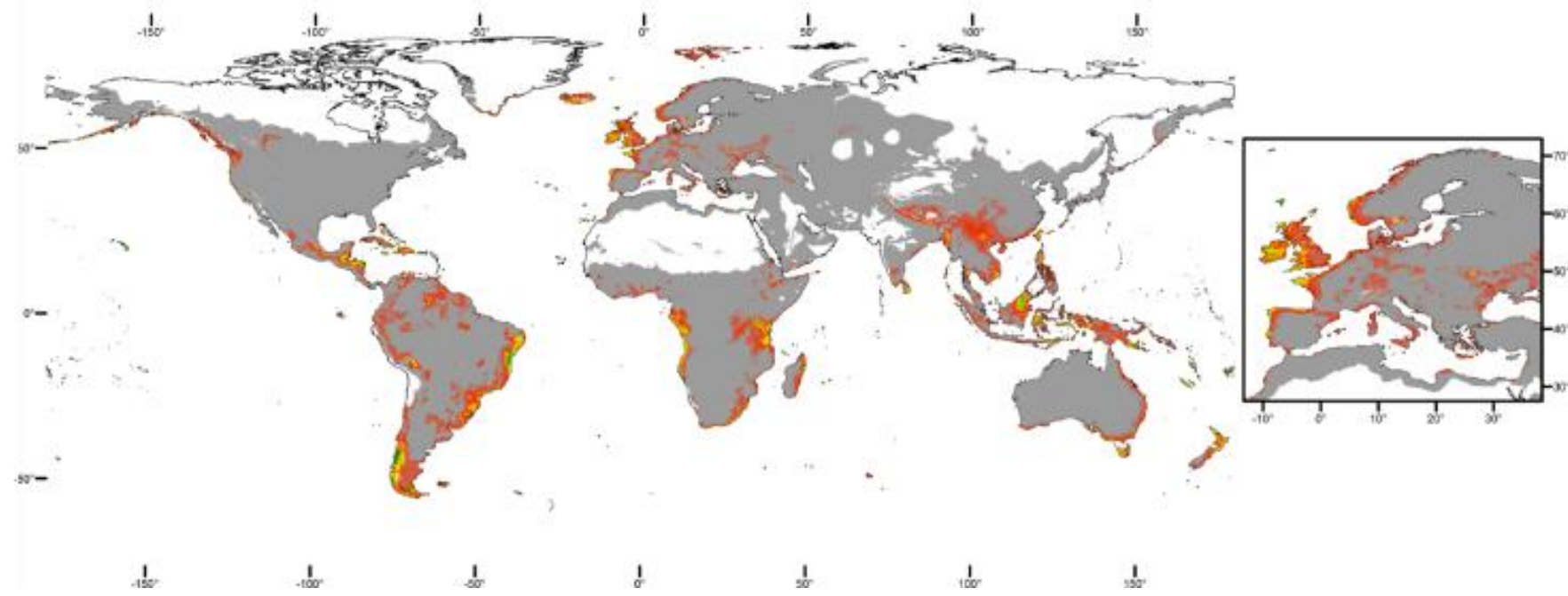

Figure 5 Global projections of predicted environmental suitability for Red Junglefowl ( $n=1559)$ based on non-indigenous observations for current climate (a), past climate (b). Suitability threshold $=0.2$; areas in white fall outside the range of calibration area 
Geographically, only limited overlap of suitable niche is observed between the indigenous and non-indigenous ENMs (Figure 6). Environmentally, niche similarity between the two was compared using ENMTools (Warren et al. 2010). "Schoener's D" (Schoener 1968) and "Hellinger's I" (Warren et al. 2008) are similarity measures which compare suitability estimates from two or more ENM, then normalise the resulting score to a value of $0-1$, where 0 indicates complete dissimilarity and 1 would indicate the niches were identical. Analysis returned overlap values of 0.76 and 0.86 respectively, suggesting that the niches are environmentally more similar than suggested by geographical overlap.

(a)

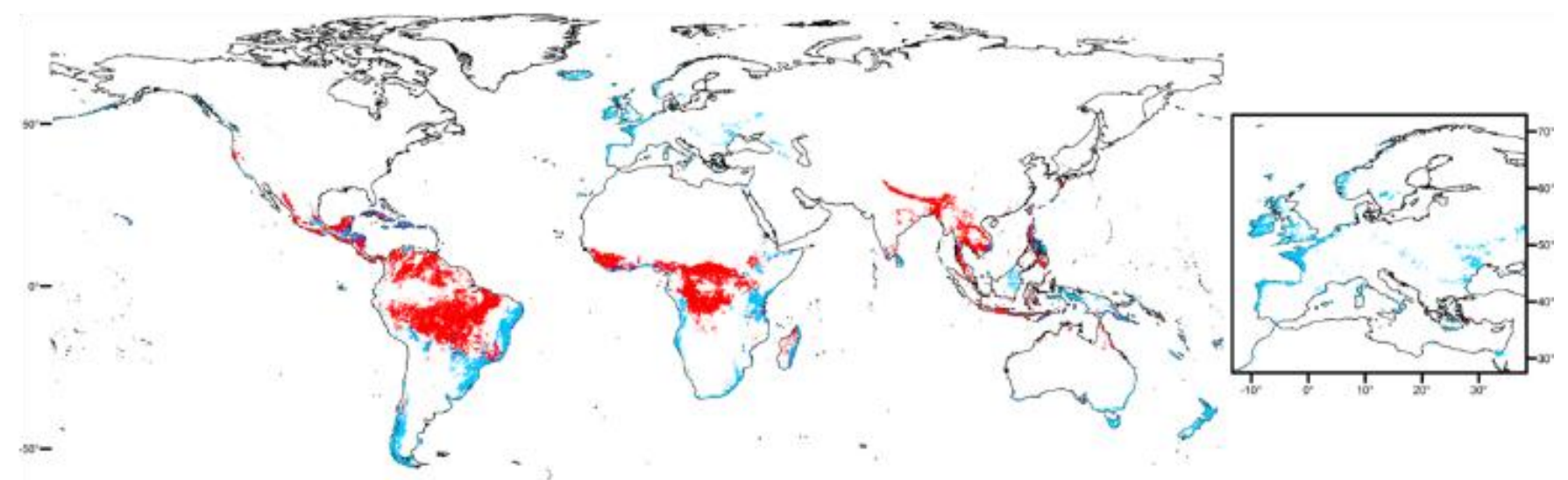

(b)
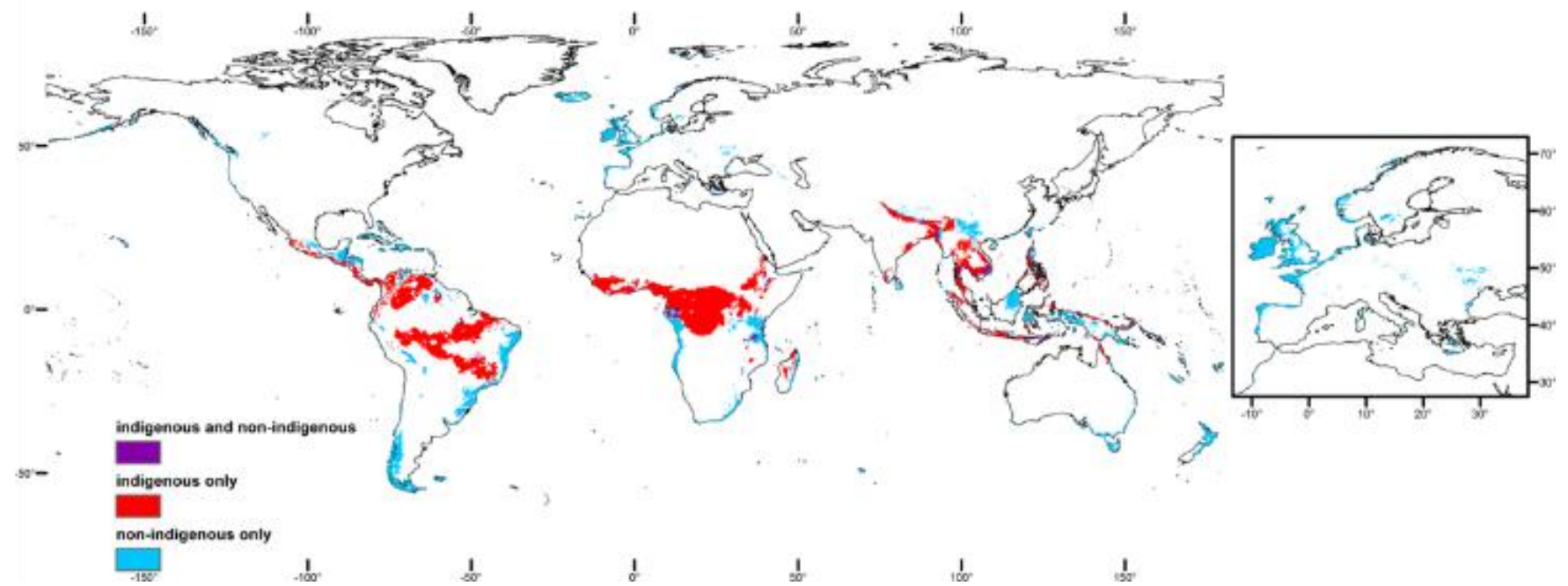

Figure 6 Areas of environmental suitability predicted to be above threshold for (a) present climate and (b) climate in 6000BP

Suitability values were extracted for each model at selected archaeological sites (Table 2). Sites chosen include those purported to have early examples of domestic fowl and/or which are found at the extremes of Europe (see Figure 7 for locations):

1. Nanzhuangtou, China (ca. 8050BC), Neolithic site with evidence for grain milling. One of the earliest sites proposed for chicken domestication worldwide (Xiang et al. 2014) but this has been contested (Peters et al. 2015; Eda et al. 2016).

2. Cishan, China (ca.5000BC). Type-site of the Cishan culture, which is associated with farming. A Neolithic settlement with dwellings, it is often cited as one of the earliest sites of chicken (West and Zhou 1988). The evidence has been recently contested and reappraised (Yuan 2010; Eda et al. 2016). 
3. Hotnitsa, Bulgaria (ca. 5000BC). Chalcolithic settlement and the earliest in Europe reported to have chicken (Boev 2009). A reappraisal of the material is in progress.

4. Mohenjo Dara, India (ca. 2500BC). Large settlement of the Harrapan civilisation. Among the earliest sites accepted to contain definite evidence of chicken from secure archaeological contexts (Zeuner 1963; Fuller 2006).

5. Cerro de la Virgen (ca. 2500BC). Argar Culture (Bronze Age) dwelling mound. Earliest claimed evidence of chicken in the Iberian peninsula (von den Driesch 1973) and of interest here due to its early date and location at the far west of Europe.

6. Eleftherna, Rethymnon, Crete (ca. 850BC). Settlement including an Early Geometric cemetery. Earliest evidence in Greece (Nobis 1998) and situated on Phoenician trade routes into Europe

7. Biskupin, Poland (ca. 650BC) Halstatt (Iron Age) period fortified settlement (Bochenski et al. 2012). Date and location may favour a northern dispersal route from Asia via Russia into Europe.

8. Alcáçova de Santarém, Portugal (ca. 800-300BC), Fortified enclosure. Earliest reliable site in the Iberian peninsula with chicken from a secure context (Davis 2006).

9. Houghton Down, Hampshire, UK (ca. 800-400BC), Two nearly complete articulated skeletons from an Early Iron Age pit within a settlement. Early evidence of chicken in the United Kingdom, at the north-west extent of Europe (Hamilton 2000).

10. Skedemosse, Öland, Sweden (ca. 15AD). Pre-Roman Iron Age fishing lake (Hagberg 1967). Among the earliest evidence in Scandinavia for chicken, and located at the northernmost extent of Europe.

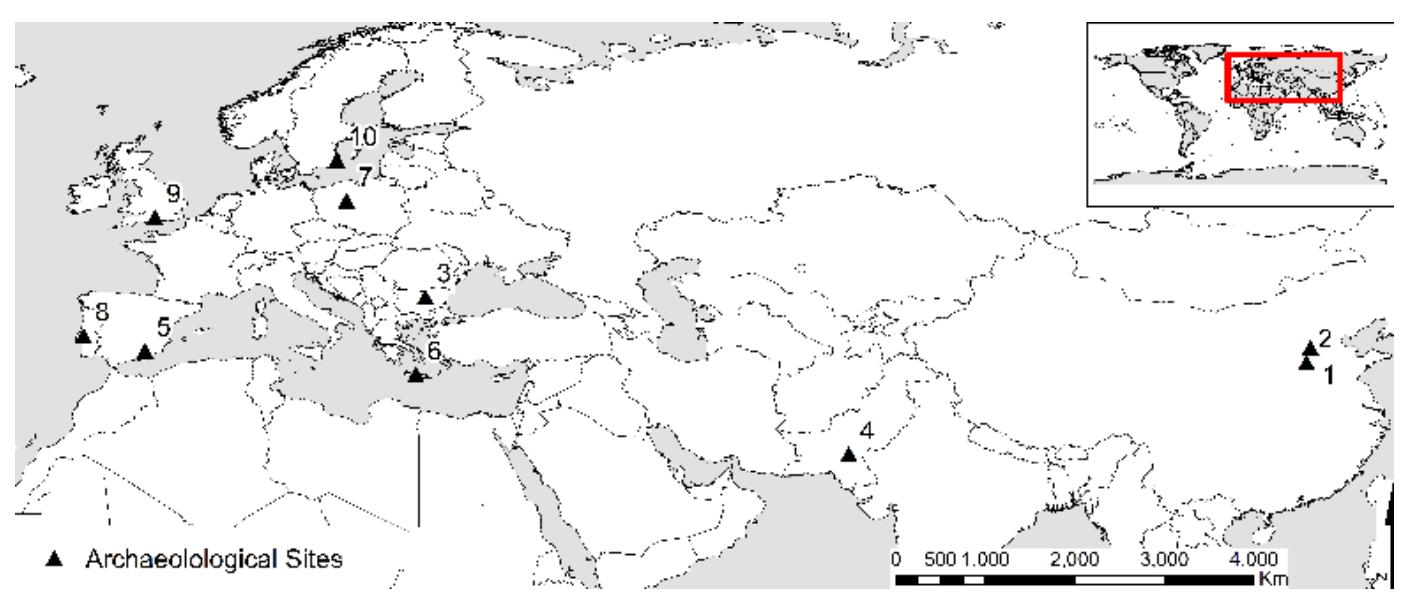

Figure 7 Location of archaeological sites mentioned in Table 2

\begin{tabular}{|c|c|c|c|c|c|c|c|c|c|c|c|c|}
\hline \multicolumn{3}{|l|}{ Model } & \multicolumn{10}{|c|}{ Archaeological Site } \\
\hline Climate & Occurences & $\begin{array}{l}\text { Suitability } \\
\text { threshold } \\
\text { value }\end{array}$ & 1 & 2 & 3 & 4 & 5 & 6 & 7 & 8 & 9 & 10 \\
\hline Present & Indigenous & 0.39 & 0.00 & 0.00 & 0.00 & 0.00 & 0.00 & 0.16 & 0.00 & 0.19 & 0.00 & 0.00 \\
\hline Present & $\begin{array}{l}\text { Non- } \\
\text { indigenous }\end{array}$ & 0.16 & 0.01 & 0.01 & 0.06 & 0.00 & 0.04 & 0.13 & 0.05 & 0.28 & 0.16 & 0.06 \\
\hline Past & Indigenous & 0.41 & 0.00 & 0.00 & 0.00 & 0.00 & 0.00 & 0.09 & 0.00 & 0.06 & 0.00 & 0.00 \\
\hline Past & $\begin{array}{l}\text { Non- } \\
\text { indigenous }\end{array}$ & 0.21 & 0.01 & 0.01 & 0.04 & 0.00 & 0.01 & 0.24 & 0.07 & 0.32 & 0.26 & 0.12 \\
\hline
\end{tabular}

Table 2 Environmental suitability (scale:0-1) for early archaeological sites containing faunal remains of domestic fowl. Above threshold values are highlighted in bold 
Our models based on indigenous occurrences indicate a complete lack of potential for suitable sets of environments at many of these locations. The poorest potential is found at the Chinese Neolithic sites and in India. Limited potential for suitable conditions may have been present in 4000BC at Eleftherna in Crete, Alcáçova de Santarém in Portugal, and Houghton Down in the UK. However, for Eleftherna and Houghton Down, it is unlikely to be suitable today and thus at the time the material was deposited.

4. Discussion: The models based on environmental conditions suitable for indigenous Red Junglefowl are largely limited to a geographical band fairly close to the equator. This suggests that if a wild Red Junglefowl was to be taken from this region and left to survive in Europe, it would be unlikely to survive without help.

Therefore, non-indigenous populations of Red Junglefowl are of great interest. Similar to the domestic chicken, these populations are likely to have been subject to some level of selection. The removal of natural barriers by virtue of human transportation has enabled these populations of Red Junglefowl to successfully inhabit environments geographically distinct from the natural habitat of the indigenous wild bird. The models indicate that they are able to survive and breed at very different latitudes and in colder climates to where the species originate. This suggests that Red Junglefowl has a broader fundamental niche than the suite of environmental conditions present in their native range suggests.

In terms of survival, environmental suitability values below the threshold for the species maximum tolerance are expected to require additional human intervention to ensure survival. The same would be true for a recently domesticated version of this species. The Red Junglefowl is a bird that is easily tamed, self-organises into hierarchical groups, and provides a good source of protein and feathers, and as such is an ideal species for domestication. However, despite millennia of domestication and selective breeding the chicken has retained traits that would make it difficult to maintain flocks in unsuitable environments, particularly without the aid of modern technology. Transporting and/or keeping a bird in enclosed environments is more challenging than for a species that does not fly, such as ungulate livestock. Keeping chickens in small confined spaces is not ideal in any case, as inability to exhibit natural behaviour, such as foraging, is displaced with abnormal behaviour, which can be aggressive (Baxter et al. 1983).

Therefore, first domestication in an area of poor environmental suitability would be unlikely to succeed. Geographical barriers limiting Red Junglefowl dispersal prior to domestication means the most likely location(s) for first domestication should be in environmentally suitable areas of the indigenous calibrated range. This would be challenging archaeologically. Gallus bones in this region are more likely to be interpreted as wild Red Junglefowl, and even if bones are found associated with domestic features, this would not necessarily indicate a domestic bird. Use of wild birds in early societies is well documented. Equally, as the tolerance of Red Junglefowl exceeds that of conditions within the native range, then archaeological bones found outside of this area (but within the ecological 
niche of non-indigenous Red Junglefowl) may not belong to domestic fowl, but wild birds selected for transportation that have subsequently escaped.

Poor environmental suitability values at locations of early archaeological evidence suggest that early chickens were either present in areas which were environmentally unsuitable for their ancestor, even at its broadest tolerance, that the sites are incorrectly dated, or that these are not chickens. Based on reappraisal of the some of the evidence, the reason may be that the remains represent a different galliform (Eda et al. 2016). If they are domestic fowl, then increased human provision would be needed to meet essential requirements, including food, water and/or shelter. The chicken was an expensive commodity, as attested by depictions in material culture and evidence of use in ritual proceedings (Sykes 2012). Decreasing suitability values by moving into higher latitudes implies greater investment of effort and resources. Colder winters require storage of feed and additional shelter, and egg-laying is affected by daylight hours, causing an issue for reproduction as well as provisioning. This is exacerbated by the fact that wild junglefowl lay eggs only in spring and although the loss of seasonal reproduction is thought to have occurred fairly early in domestication, the date of this adaptation remains unclear (Girdland Flink et al. 2014).

In terms of dispersal routes, the models indicate that a northern route via China and Russia into Eastern Europe would be environmentally challenging. Areas predicted as suitable by models based on non-indigenous observations do, however, correspond well with Greek and Phoenician trade routes through the Mediterranean and up into southern Britain and Ireland (Becker 2013). The start of these routes also link up with known Bronze Age commercial roads through the Near and Middle East (Covington 2013). Suitable environmental conditions would likely improve potential for survival of an early domestic descendent of the Red Junglefowl into Europe via this route. A lack of potential for suitable sets of environments for much of the rest of Europe suggests that the chicken needed to adapt further by the time it reached parts of central and northern Europe, and/or would have required substantial human investment to survive in such climates outside of the environmental tolerance of its ancestor.

Analysis of the habitat of occurrences both within and outside of the native range may be able to answer questions regarding the extent of adaptation under domestication, as related to climate. Efforts are currently being made to reappraise the faunal evidence in Bulgaria and other early sites with domestic fowl. This may prove interesting, especially if sites with poor environmental potential are shown to be of correct date, as this may indicate a fairly rapid adaptation to climate on the part of the chicken in otherwise unsuitable conditions.

5. Conclusions: Our analyses confirm that the climate of Europe is not suitable for indigenous Red Junglefowl, or by extension, its descendant in early stages of domestication. A Red Junglefowl taken from Asia to Europe today is unlikely to find conditions suitable for unaided survival. This suggests that early domestic fowl could not just be transported and left to disperse, survive and breed. Rather, it provides an interesting example of the human investment 
required to sustain a new domestic species, especially since sites containing early examples of chicken are likely to have lacked suitable environmental conditions. Based on environmental considerations, first domestication is likely to have occurred in the native range of the species and not in areas such as northern China, where environmental conditions are likely to have been entirely unsuitable. Occurrences of Red Junglefowl outside of its natural range suggests that Red Junglefowl can, and have, acclimated to alternative environments. This suggests that the environmental niche of the species may be broader than might be suspected based on conditions within its native range. It also suggests that a dispersal route through the Mediterranean into Europe has the best potential for presence of environmental conditions to aid survival of a new domestic species.

Acknowledgments: This research was funded by Bournemouth University, in association with the AHRC (Grant No AH/L006979/1). We would like to thank Zlatozar Boev for his assistance and cooperation with the early Bulgarian remains, and the many contributors to the GBIF database who made this research possible. We would also like to thank two anonymous reviewers for their very helpful and constructive comments. 
Araujo, M. B., Ferri-Yanez, F., Bozinovic, F., Marquet, P. A., Valladares, F. and Chown, S. L., 2013. Heat freezes niche evolution. Ecology Letters, 16 (9), 1206-1219.

Banks, W. E., Antunes, N., Rigaud, S. and Francesco, d. E., 2013. Ecological constraints on the first prehistoric farmers in Europe. Journal of Archaeological Science, 40 (6), 2746-2753.

Baxter, S. H., Baxter, M. R. and MacCormack, J. A. C., 1983. Farm Animal Housing and Welfare. Vol. 24. Netherlands: Springer.

Becker, C., 2013. Hühner auf einem langen Seeweg gen Westen - Frühe Nachweise von Gallus domesticus aus der phönizisch-punischen Niederlassung von Mogador, Marokko. In: Kroll, H. J. and Kroll, H. J., eds. Von Sylt bis Kastanas : Festschrift für Helmut Johannes Kroll. Neumunster: Wachholtz, 225-238.

Bochenski, Z., Bochesnski, Z. M. and Tomek, T., 2012. A History of Polish Birds: Polish Academy of Sciences.

Bochenski, Z. M., 2008. Identification of skeletal remains of closely related species: the pitfalls and solutions. Journal of Archaeological Science, 35 (5), 1247-1250.

Boev, Z., 2009. Avian Remains from the Late Chalcolithic Settlement near Hotnitsa Village (Veliko Tarnovo Region, CN Bulgaria). Acta Zoologica Bulgarica, 61 (1), 49-54.

CGIAR Consortium for Spatial Information, 2008. Resampled SRTM data to 250m resolution (based on SRTM 90m Digital Elevation Model) [online]. Available from: http://srtm.csi.cgiar.org/ [Accessed $16 / 12 / 2015]$.

Chemnitz, C. and Becheva, S., 2014. Meat Atlas. Facts and figures about the animals we eat. [online]. Jointly published by the Heinrich Böll Foundation, Berlin, Germany, and Friends of the Earth Europe, Brussels, Belgium.

Covington, R., 2013. Roads of Arabia. Saudi Aramco World, 64 (7), 2.

Davis, S. J. M., 2006. Faunal remains from Alcáçova de Santarém, Portugal. Vol. 43. Lisbon: Instituto português de arqueologia.

Eda, M., Lu, P., Kikuchi, H., Li, Z., Li, F. and Yuan, J., 2016. Reevaluation of early Holocene chicken domestication in northern China. Journal of Archaeological Science, 67, 25-31.

Elith, J., Graham, C. H., Anderson, R. P., Dudík, M., Ferrier, S., Guisan, A., Hijmans, R. J., Huettmann, F., Leathwick, J. R., Lehmann, A., Li, J., Lohmann, L. G., Loiselle, B. A., Manion, G., Moritz, C., Nakamura, M., Nakazawa, Y., Jacob Mc, C. O., Peterson, A. T., Phillips, S. J., Richardson, K., Scachetti-Pereira, R., Schapire, R. E., Soberón, J., Williams, S., Wisz, M. S., Zimmermann, N. E. and Araujo, M., 2006. Novel Methods Improve Prediction of Species' Distributions from Occurrence Data. Ecography, 29 (2), 129-151.

Eriksson, J., Larson, G., Gunnarsson, U., Bed'hom, B., Tixier-Boichard, M., Strömstedt, L., Wright, D., Jungerius, A., Vereijken, A., Randi, E., Jensen, P. and Andersson, L., 2008. Identification of the yellow skin gene reveals a hybrid origin of the domestic chicken. Plos Genetics, 4 (2).

FAO/IIASA/ISRIC/ISS-CAS/JRC, 2009. Harmonized World Soil Database (version 1.1) [online]. Available from: http://databasin.org/datasets/92cd21cec56a48289ebaeccaa75d6ada [Accessed 7/12/2015].

Ficetola, G. F., Thuiller, W. and Miaud, C., 2007. Prediction and validation of the potential global distribution of a problematic alien invasive species - the American bullfrog. Diversity and Distributions, 13 (4), 476-485.

Fitzpatrick, S. M. and Callaghan, R., 2009. Examining dispersal mechanisms for the translocation of chicken (Gallus gallus) from Polynesia to South America. Journal of Archaeological Science, 36 (2), 214-223.

Fuller, D. Q., 2006. Agricultural Origins and Frontiers in South Asia: A Working Synthesis. Journal of World Prehistory, 20 (1), 1-86.

GBIF.org (11th February 2016), GBIF Occurrence Download. Available from: 11th February 2016].

Gering, E., Johnsson, M., Willis, P., Getty, T. and Wright, D., 2015. Mixed ancestry and admixture in Kauai's feral chickens: invasion of domestic genes into ancient Red Junglefowl reservoirs. Molecular Ecology, Special Issue: Invasion Genetics: The Baker and Stebbins Legacy.

Girdland Flink, L., Allen, R., Barnett, R., Malmström, H., Peters, J., Eriksson, J., Andersson, L., Dobney, K. and Larson, G., 2014. Establishing the validity of domestication genes using DNA from ancient chickens. Proceedings of the National Academy of Sciences, 111 (17), 6184-6189.

Gongora, J., Rawlence, N. J., Mobegi, V. A., Jianlin, H., Alcalde, J. A., Matus, J. T., Hanotte, O., Moran, C., Austin, J. J., Ulm, S., Anderson, A. J., Larson, G. and Cooper, A., 2008. Indo-European and Asian 
origins for Chilean and Pacific chickens revealed by mtDNA. Proceedings of the National Academy of Sciences, 105 (30), 10308-10313.

Hagberg, U. E., 1967. The archaeology of Skedemosse. In collaboration with Margareta Beskow. With geological and zoological contributions by Lars-König Königsson and Johannes Lepiksaar. Stockholm: The Royal Swedish Academy of Letters, History and Antiquities.

Hamilton, J., 2000. Animal bones. In: Poole, B. C. a. C., ed. The Danebury environs programme : the prehistory of a Wessex landscape. Vol. 2, Part 6, Houghton Downs, Stockbridge, Hants, 1994. Oxford: University of Oxford, Committee for Archaeology, 67-73.

Harrison, C. J. O., 1980. A re-examination of British Devensian and earlier holocene bird bones in the British Museum (natural history). Journal of Archaeological Science, 7, 53-68.

Hijmans, R. J., Cameron, S. E., Parra, J. L., Jones, P. G. and Jarvis, A., 2005. Very high resolution interpolated climate surfaces for global land areas. International Journal of Climatology, 25 (15), 1965-1978.

Kanginakudru, S., Metta, M., Jakati, R. D. and Nagaraju, J., 2008. Genetic evidence from Indian red jungle fowl corroborates multiple domestication of modern day chicken. BMC Evolutionary Biology, 8, 1-14.

Khaliq, I., Hof, C., Prinzinger, R., Böhning-Gaese, K. and Pfenninger, M., 2014. Global variation in thermal tolerances and vulnerability of endotherms to climate change. Proceedings of the Royal Society $B$, 281 (1789).

Kyselý, R., 2010. Review of the oldest evidence of domestic fowl Gallus gallus f. domestica from the Czech Republic in its European context. Acta zoologica cracoviensia, 53A (1-2), 9-34.

Liu, C., Berry, P. M., Dawson, T. P. and Pearson, R. G., 2005. Selecting thresholds of occurrence in the prediction of species distributions. Ecography, 28 (3), 385-393.

Liu, Y. P., Wu, G. S., Yao, Y. G., Zhang, Y. P., Miao, Y. W., Ding, Z. L., Palanichamy, M. G., Luikart, G., Beja-Pereira, A. and Baig, M., 2006. Multiple maternal origins of chickens: Out of the Asian jungles. Molecular Phylogenetics and Evolution, 38 (1), 12-19.

Miao, Y. W., Peng, M. S., Wu, G. S., Ouyang, Y. N., Yang, Z. Y., Yu, N., Liang, J. P., Pianchou, G., BejaPereira, A., Mitra, B., Palanichamy, M. G., Baig, M., Chaudhuri, T. K., Shen, Y. Y., Kong, Q. P., Murphy, R. W., Yao, Y. G. and Zhang, Y. P., 2013. Chicken domestication: an updated perspective based on mitochondrial genomes. Heredity, 110 (3), 277-282.

Nasa Earth Observations, 2015. Vegetation Index [NDVI] (1 month - Terra/MODIS) [online]. Available from: http://neo.sci.gsfc.nasa.gov/view.php?datasetld=MOD13A2 M NDVI\&year=2008 7/12/2015].

[Accessed

Nobis, G., 1998. Studien an Tierresten aus archäologischen Grabungen Poros bei Iraklion und Eléftherna bie Arkadhi :ein Beitrag zur antiken Wild- und Haustierfauna Kretas. In: Anreiter, P., ed. Man and the Animal World. Archaeolingua Alapitvany, 409-433.

Perry-Gal, L., Erlich, A., Gilboa, A. and Bar-Oz, G., 2015. Earliest economic exploitation of chicken outside East Asia: Evidence from the Hellenistic Southern Levant. Proceedings of the National Academy of Sciences, 112 (32), 9849-9854.

Peters, J., Lebrasseur, O., Best, J., Miller, H., Fothergill, T., Dobney, K., Thomas, R. M., Maltby, M., Sykes, N., Hanotte, O., O'Connor, T., Collins, M. J. and Larson, G., 2015. Questioning new answers regarding Holocene chicken domestication in China. Proceedings of the National Academy of Sciences, 112 (19), E2415-E2415.

Peterson, A. T. and Brisbin, I. L., 1998. Genetic endangerment of wild Red Junglefowl Gallus gallus? Bird Conservation International, 8 (4), 387-394.

Phillips, S. J., Anderson, R. P. and Schapire, R. E., 2006. Maximum entropy modeling of species geographic distributions. Ecological Modelling, 190 (3-4), 231-259.

Phillips, S. J., Dudik, M. and Schapire, R. E., 2004. A Maximum Entropy Approach to Species Distribution Modeling. Proceedings of the 21st International Conference on Machine Learning, Banff, Canada, 2004 [online], 655-662.

Phillips, S. J., Dudík, M., Elith, J., Graham, C. H., Lehmann, A., Leathwick, J. and Ferrier, S., 2009. Sample selection bias and presence-only distribution models: implications for background and pseudoabsence data. Ecological Applications, 19 (1), 181-197.

Schoener, T., W., 1968. The Anolis Lizards of Bimini: Resource Partitioning in a Complex Fauna. Ecology, 49 (4), 704-726.

Stager, M., Pollock, H. S., Benham, P. M., Sly, N. D., Brawn, J. D. and Cheviron, Z. A., 2015. Disentangling environmental drivers of metabolic flexibility in birds: the importance of temperature extremes versus temperature variability. Ecography, n/a-n/a. 
Stewart, J., 2005. The use of modern geographical ranges in the identification of archaeological bird remains. Documenta Archaeobiologiae, 3, 43-56.

Stewart, J. R., 2007. An evolutionary study of some archaeologically significant avian taxa in the quaternary of the western Palaearctic. Oxford: Archaeopress, 2007.

Storey, A. A., Athens, J. S., Bryant, D., Carson, M., Emery, K., deFrance, S., Higham, C., Walter, R., Huynen, L., Intoh, M., Jones, S., Kirch, P. V., Ladefoged, T., McCoy, P., Morales-Muñiz, A., Quiroz, D., Reitz, E., Robins, J. and Matisoo-Smith, E., 2012. Investigating the global dispersal of chickens in prehistory using ancient mitochondrial dna signatures. PLOS ONE, 7 (7).

Storey, A. A., Ladefoged, T. and Matisoo-Smith, E. A., 2008. Counting your chickens: density and distribution of chicken remains in archaeological sites of Oceania. International Journal of Osteoarchaeology, 18 (3), 240.

Storey, A. A., Ramírez, J. M., Quiroz, D., Burley, D. V., Addison, D. J., Walter, R., Anderson, A. J., Hunt, T. L., Athens, J. S., Huynen, L. and Matisoo-Smith, E. A., 2007. Radiocarbon and DNA evidence for a pre-Columbian introduction of Polynesian chickens to Chile. Proceedings of the National Academy of Sciences, 104 (25), 10335-10339.

Strid, L., 2015. Animal bone. In: P. Andrews, P. B., A. P. Fitzpatrick and K. Welsh, ed. Digging at the Gateway: archaeological landscapes of south Thanet. The Archaeology of East Kent Access (Phase II), Volume 2: The Finds, Environment and Dating Reports. Oxford: Oxford Archaeology, 444-460.

Swets, J. A., 1988. Measuring the accuracy of diagnostic systems. Science, 240 (4857), 1285-1293.

Sykes, N., 2012. A social perspective on the introduction of exotic animals: the case of the chicken. World Archaeology, 44 (1), 158-169.

Thomson, V. A., Lebrasseur, O., Austin, J. J., Hunt, T. L., Burney, D. A., Denham, T., Rawlence, N. J., Wood, J. R., Gongora, J., Girdland Flink, L., Linderholm, A., Dobney, K., Larson, G. and Cooper, A., 2014. Using ancient DNA to study the origins and dispersal of ancestral Polynesian chickens across the Pacific. Proceedings Of The National Academy Of Sciences Of The United States Of America, 111 (13), 4826-4831.

von den Driesch, A., 1973. Fauna, Klima und Landschaft im Süden der Iberischen Halbinsel während der Metallzeit. In: Matolcsi, J., ed. Domestikationsforschung und Geschichte der Haustiere. Budapest: Akadémiai Kiadó, 245-255.

Warren, D. L., Glor, R. E. and Turelli, M., 2008. Environmental niche equivalency versus conservatism: quantitative approaches to niche evolution. Evolution, 62 (11), 2868-2883.

Warren, D. L., Glor, R. E. and Turelli, M., 2010. ENMTools: a toolbox for comparative studies of environmental niche models. Ecography, 33 (3), 607-611.

West, B. and Zhou, B. X., 1988. Did chickens go North? New evidence for domestication. Journal of Archaeological Science, 15 (5), 515-533.

Xiang, H., Gao, J., Yu, B., Hofreiter, M. and Zhao, X., 2015. Reply to Peters et al.: Further discussions confirm early Holocene chicken domestication in northern China. Proceedings of the National Academy of Sciences, 112 (19), E2416-E2416.

Xiang, H., Gao, J., Yu, B., Zhou, H., Cai, D., Zhang, Y., Chen, X., Wang, X., Hofreiter, M. and Zhao, X., 2014. Early Holocene chicken domestication in northern China. Proceedings of the National Academy of Sciences, 111 (49), 17564-17569.

Yuan, J., 2010. Zooarchaeological Study on the Domestic Animals in Ancient China. Quaternary Sciences, 30 (2), 298-306.

Zeuner, F. E., 1963. A history of domesticated animals. London: Hutchinson. 